Indonesian Journal of Physics

Vol 19 No. 3, July 2008

\title{
Mechanical Alloying of Fe-C System Based Alloy
}

\author{
Nurul Taufiqu Rochman \\ Research Center for Physics, Indonesian Institute of Sciences \\ Kawasan PUSPIPTEK Serpong, Tangerang 15310
}

\begin{abstract}
This paper reviews the research of the author's group regarding mechanical alloying (MA) of Fe-C system based alloy over the last ten years. Powder mixtures of Fe-xC-yM ( $x$ and $y=0 \sim 6$ mass \%, M: additive element such as Mn, $\mathrm{Si}, \mathrm{Cr}$ ) were mechanically alloyed (MAed) by using a planetary ball mill under Ar gas atmosphere for various time up to $100 \mathrm{~h}$. The MAed powders then were characterized by X-ray diffraction (XRD), scanning electron microscopy (SEM) and differential thermal analysis (DTA). First, effect of MA time on powders particles was described. Effects of other MA conditions such as temperature, rotation speed and additive elements were then discussed in detail. In the Fe-C system based alloys, amorphization of graphite powders occur first during the early stage of MA and super-saturated iron solid solution is then formed and at the same time, the crystallite size becomes smaller. The carbon content reaches its limitation (about 1.30 at \%). The condition of MA gave an effect to the alloying process.
\end{abstract}

Keywords: Fe-C system based alloy, MA temperature, Rotation speed, Carbon content, Amorphization, Nanoparticle

\section{Intoduction}

Mechanical properties of steel materials (Fe-C system based alloys) are dependent on amount, morphology, size and distribution of $\mathrm{Fe}_{3} \mathrm{C}$ and graphite in the $\alpha$-Fe matrix. The increase in the amount of $\mathrm{Fe}_{3} \mathrm{C}$ leads to the increase in toughness of materials. In cast irons, a coarse ledeburite structure is formed due to eutectic reaction in which liquid metal is transformed into $\alpha-\mathrm{Fe}$ and $\mathrm{Fe}_{3} \mathrm{C}$ during solidification. Cast irons also contain flaky or spheroidal graphite. The presence of coarse ledeburite structure and large-sized graphite results in a decrease in both ductility and toughness of cast iron.

In the last three decades, mechanical alloying (MA) has been utilized as one of alloying technique to attain very fine alloying powders by mechanically mixing several element powders. By means of highenergy collisions, MA represents a new nonequilibrium process for producing metastable materials such as amorphous ${ }^{1,2)}$, solid solution ${ }^{2)}$ and ultra-fine powders ${ }^{3,4)}$. If iron and graphite powder particles can be refined by $\mathrm{MA}$, new $\mathrm{Fe}-\mathrm{C}$ system materials with excellent properties such as high hardness ${ }^{5,6)}$, strength and wear resistance may be attainable. However, there have been only few reports $^{7,8)}$ regarding the alloying mechanism of $\mathrm{Fe}-\mathrm{C}$ system based alloy during MA process, and the mechanism is still not that well understood.

Therefore, in the present paper, mechanical alloying of Fe-C system alloy is studied fundamentally. The effect of MA conditions such as temperature, speed and additive elements were discussed in detail.

\section{Experimental Procedure}

Table 1 shows elemental powders used as starting materials. While Table 2 shows composition of mixed powders. Mixtures powders were charged in $450 \mathrm{~cm}^{3}$ hardened steel vials with 2 types of austenitic stainless steel balls $(\phi 12 \mathrm{~mm}: \phi 7 \mathrm{~mm}=1: 1)$ under an
Ar atmosphere in a glove box. The powder-to-ball ratio was approximately 1: 8. Mechanical alloying runs were carried out using a planetary ball mill for various times up to $100 \mathrm{~h}$. In order to study the effect of MA temperatures, three different temperatures of MA were carried out for Fe-6C mixture powders. While various rotation speeds $(80,100$ and $120 \mathrm{rpm})$ of MA were also carried out for Fe-7C-6Mn system mixture powders. In order to study the effect of additive elements such as $\mathrm{Si}, \mathrm{Cr}$, and $\mathrm{Mn}$ on the MA process, various concentrations of elements were added. The MAed powders were characterized by Xray diffraction (XRD), differential thermal analysis (DTA) and SEM. DTA was performed under an Ar atmosphere at a heating rate of $0.33 \mathrm{~K} / \mathrm{s}$.

Table 1. Powders used as starting materials

\begin{tabular}{|c|c|c|c|c|c|}
\hline $\begin{array}{c}\text { Elemental } \\
\text { Powders }\end{array}$ & \multicolumn{2}{|c|}{ Manufacturer } & LOT & $\begin{array}{l}\text { Size } \\
(\mu \mathrm{m})\end{array}$ & $\begin{array}{c}\text { Purity } \\
\text { (mass\%) }\end{array}$ \\
\hline $\mathrm{Fe}$ & \multicolumn{2}{|c|}{$\begin{array}{l}\text { Mitsuwa } \\
\text { Chem.Co., Ltd. }\end{array}$} & 53496 & 5 & 99.5 \\
\hline $\mathrm{C}$ & \multicolumn{2}{|c|}{ Rare Met. Co., Ltd } & $30209-15$ & $<78$ & 99.9 \\
\hline $\mathrm{Si}$ & $\begin{array}{l}\text { Furuuchi } \\
\text { Co., Ltd. }\end{array}$ & Chem. & 50817 & $<85$ & 99.9 \\
\hline $\mathrm{Cr}$ & $\begin{array}{l}\text { Furuuchi } \\
\text { Co., Ltd. }\end{array}$ & Chem. & N2676 & $<85$ & 99.9 \\
\hline $\mathrm{Mn}$ & $\begin{array}{l}\text { The } \\
\text { Corporat }\end{array}$ & Nilaco & 284101 & 5 & 99.98 \\
\hline
\end{tabular}

Table 2 Symbols of mixtures powders(mass\%).

\begin{tabular}{lccccc}
\hline \multicolumn{1}{c}{ Mark } & Fe & C & Si & Cr & Mn \\
\hline $\mathrm{Fe}-0.4 \mathrm{C}$ & 99.6 & 0.4 & - & - & - \\
\hline $\mathrm{Fe}-0.6 \mathrm{C}$ & 99.4 & 0.6 & - & - & - \\
\hline $\mathrm{Fe}-1 \mathrm{C}$ & 99.0 & 1.0 & - & - & - \\
\hline $\mathrm{Fe}-1.5 \mathrm{C}$ & 98.5 & 1.5 & - & - & - \\
\hline $\mathrm{Fe}-2 \mathrm{C}$ & 98 & 2.0 & - & - & - \\
\hline $\mathrm{Fe}-4 \mathrm{C}$ & 96 & 4.0 & - & - & - \\
\hline $\mathrm{Fe}-6 \mathrm{C}$ & 94 & 6 & - & - & - \\
$\mathrm{Fe}-6 \mathrm{C}-2 \mathrm{Si}$ & 92 & 6 & 2 & - & - \\
$\mathrm{Fe}-7 \mathrm{C}$ & 93 & 7 & - & - & - \\
$\mathrm{Fe}-8 \mathrm{C}$ & 92 & 8 & - & - & - \\
$\mathrm{Fe}-8 \mathrm{C}-1.2 \mathrm{Cr}$ & 90.8 & 8 & - & 1.2 & - \\
$\mathrm{Fe}-8 \mathrm{C}-2.5 \mathrm{Cr}$ & 89.5 & 8 & - & 2.5 & - \\
$\mathrm{Fe}-8 \mathrm{C}-5 \mathrm{Cr}$ & 87 & 8 & - & 5 & - \\
$\mathrm{Fe}-7 \mathrm{C}-2 \mathrm{Mn}$ & 91 & 7 & - & - & 2 \\
$\mathrm{Fe}-7 \mathrm{C}-4 \mathrm{Mn}$ & 89 & 7 & - & - & 4 \\
$\mathrm{Fe}-7 \mathrm{C}-6 \mathrm{Mn}$ & 87 & 7 & - & - & 6 \\
\hline \hline
\end{tabular}




\section{Results and Discussion}

\subsection{Effect of MA time}

Figure 1 shows SEM images of MAed Fe-7C mixture powders. Morphologically, as-received graphite powder is irregular, while iron powder is spherical (Figure (a)). During the early stage of MA (for $16 \mathrm{~h}$ ), morphology of ductile iron powder changes from spherical to flake-like with a high aspect ratio. While, irregular graphite powder cannot be observed. The flake-like powders disappear when MA time exceeds $60 \mathrm{~h}$ and become agglomeration of ultra-fine particles (nano-meter order) as shown in Figure (c) and (d).
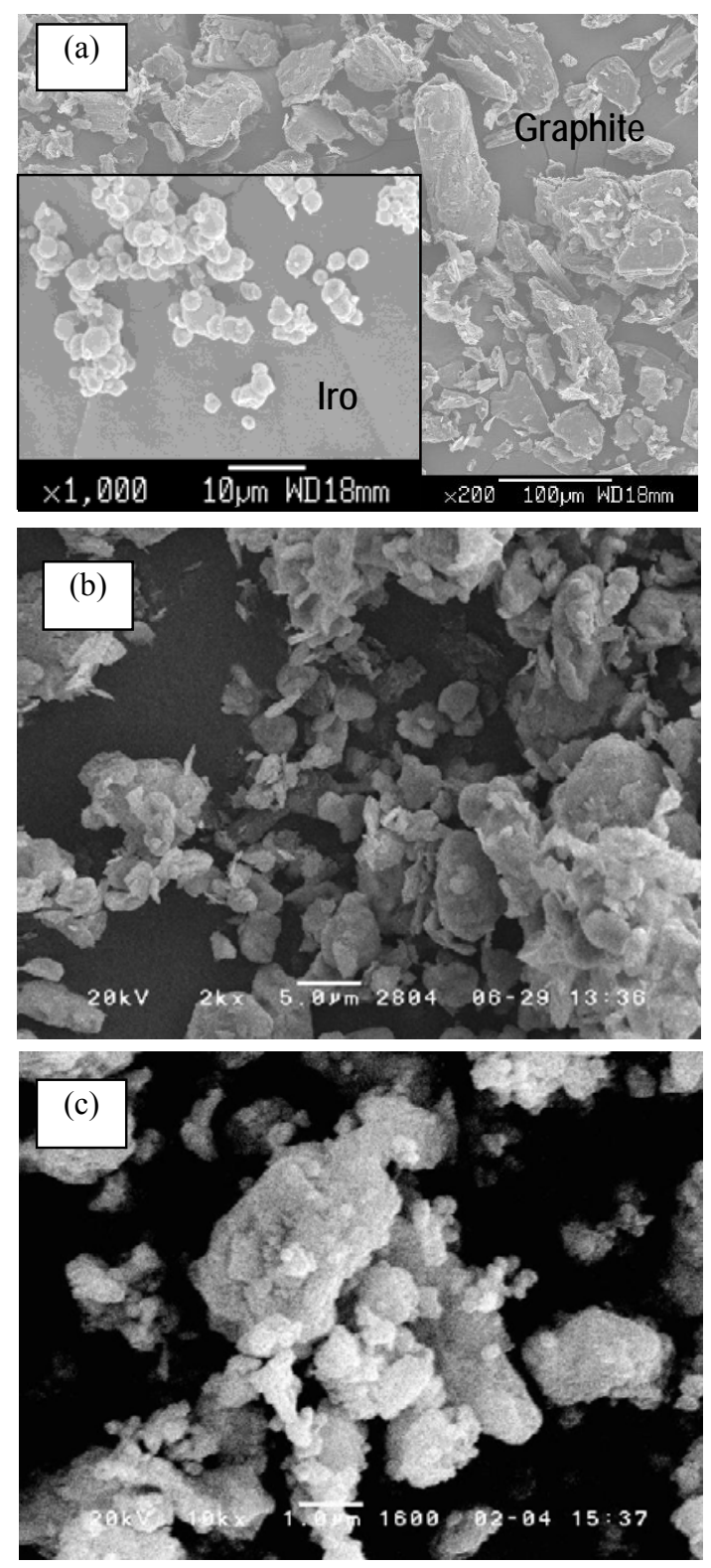

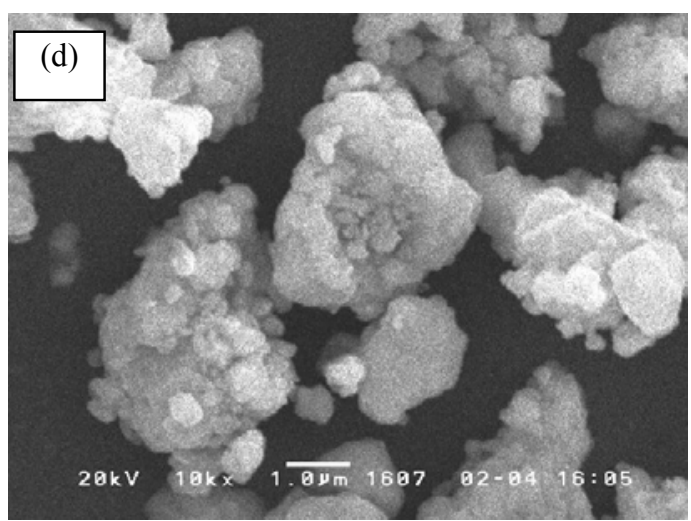

Figure 1. SEM image of (a) as-received graphite and iron powders and Fe-7C mixture powders MAed for (b) $16 \mathrm{~h}$, (c) $60 \mathrm{~h}$ and (d) $100 \mathrm{~h}$.

Figure 2 shows XRD pattern of Fe-7C mixture powders MAed for various time. Diffraction peaks of iron and graphite are clearly observed first. Diffraction peak of graphite cannot be detected when MA time exceeds $16 \mathrm{~h}$. Nagano et al., ${ }^{9)}$ reported that layer structure of graphite is transformed into an amorphous-like structure after mechanical milling according to the XRD pattern. Thus, disappearance of graphite peak after $16 \mathrm{~h}$ indicates that crystalline graphite changes into amorphous phase and refinement of graphite powders progress well so that they can not be observed in Figure 1 (b). It is assumed that very fine graphite powder particles stick around deformed iron particle. Meanwhile, the iron diffraction peaks broaden with MA time. This may be due to grain refinement ${ }^{10)}$ and amorphization ${ }^{11)}$ of iron powders during MA process. As shown in Figure 2, the peak position of iron shifts to a lower angle when MA time is long. This suggests that carbon atoms dissolve into iron and a super-saturated iron solid solution is formed. Carbon content of iron solid solution can be estimated by measuring the change in the lattice parameter of iron and substituting this value in the equation proposed by Fasiska et al. ${ }^{(12)}$. It can be expressed by the following equation:

$$
a=0.28664+0.00084 C
$$

where $a$ is the lattice parameter $(\mathrm{nm})$ and $C$ is the carbon content of iron solid solution (at \%). Figure 3 shows changes in lattice parameter and carbon content of Fe-7C mixture powders as a function of MA time. The lattice parameter and carbon content do not increase significantly during early stage of MA. However, they increase remarkably when MA time exceeds $16 \mathrm{~h}$. It is suggested that carbon atoms which stick in the surface of iron powders begin entering the lattice iron, resulting in the increase in carbon content abruptly after MAed for $16 \mathrm{~h}$. 


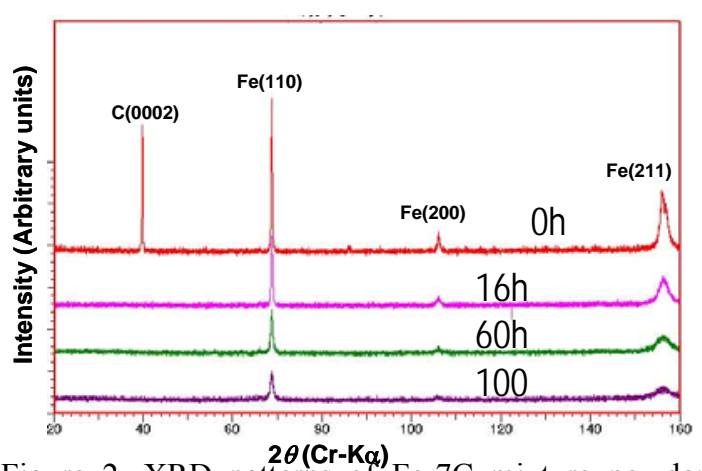

Figure 2. XRD patterns of $\mathrm{Fe}-7 \mathrm{C}$ mixture powders MAed for various MA time.

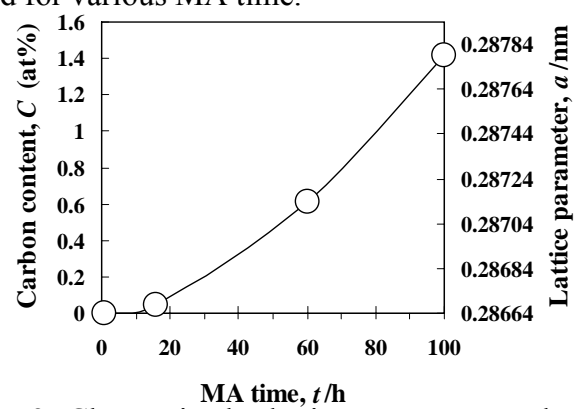

Figure 3. Change in the lattice parameter and carbon content of iron solid solution as a function of MA time.

Figure 4 shows lattice parameter and carbon content of iron solid solution as a function of carbon concentration in mixed powders. Carbon content increases abruptly with the increase of carbon concentration first. However, it saturates when carbon concentration exceeds 4 mass $\%$. This indicates that the solubility of carbon atoms in the super-saturated iron solid solution has a limit to be about 0.28 mass \% or 1.30 at $\%(0.28776 \mathrm{~nm})$ at $100 \mathrm{~h}^{(5)}$. It was reported that the non-equilibrium solubility of carbon in the $\mathrm{Cu}-\mathrm{C}$ system also has a limitation, even by using MA method $^{(13)}$. It is suggested that all of the carbon atoms are not adopted for the formation of super-saturated solid solution, but a part of carbon atoms exists as $\mathrm{Fe} / \mathrm{C}$ amorphous phase and free amorphous graphite $^{(14)}$.

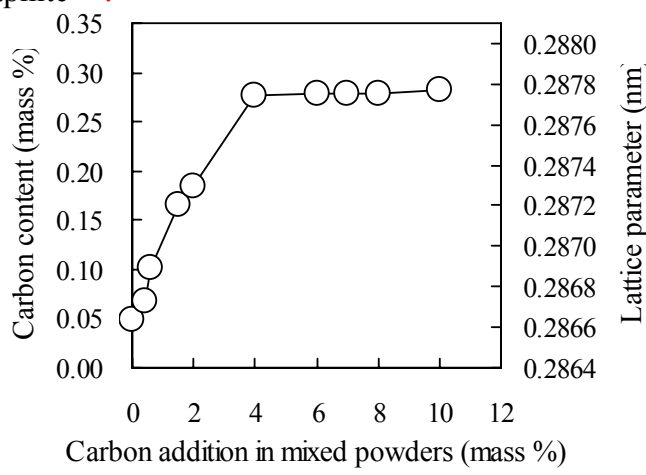

Figure 4. Change in the lattice parameter and carbon content of iron solid solution MAed for $100 \mathrm{~h}$ as a function of MA time.

\subsection{Effect of MA temperature}

Figure 5 shows changes in the lattice parameter and carbon content for various temperatures with MA time. For temperatures of 323 and $293 \mathrm{~K}$, the lattice parameter and carbon content increase remarkably when MA time exceeds $20 \mathrm{~h}$. In these cases, the increase for $323 \mathrm{~K}$ is larger than that for $293 \mathrm{~K}$. For $323 \mathrm{~K}$, the carbon content of iron solid solution is saturated after $60 \mathrm{~h}$. For $293 \mathrm{~K}$, the carbon content does not reach this value even after $80 \mathrm{~h}$ of MA. However it may possibly be reached after about $120 \mathrm{~h}$ by extrapolating the linear relationship of the carbon content with MA time. On the other hand, for $253 \mathrm{~K}$, before $40 \mathrm{~h}$ of MA, most of the carbon atoms do not dissolve into iron. When the MA time exceeds $40 \mathrm{~h}$, the carbon content drastically increases and its increasing rate is larger than that for $293 \mathrm{~K}$. Thus, the time to start making super-saturated solid solution for $253 \mathrm{~K}$ is longer than that for $293 \mathrm{~K}$, but the time to reach the non-equilibrium solubility of carbon is shorter than that for $293 \mathrm{~K}$. These results clearly indicate that the solution of carbon atoms during MA is influenced by MA temperatures.

The change in the integral width of the iron diffraction peak is due to the changes in crystallite size and lattice strain. This relation is given as follows ${ }^{(15)}$ :

$$
\beta \cos \theta / \lambda=2 \varepsilon \sin \theta / \lambda+1 / L
$$

where $\lambda, \theta, \beta, \varepsilon, L$ is the X-ray wave length, diffraction angle, integral width, lattice strain and crystallite size, respectively. According to this equation, if $\beta \cos \theta / \lambda$ is taken as vertical axis and $\sin$ $\theta / \lambda$ as horizontal axis, the linear relation can be obtained. The crystallite size and lattice strain can be found from the reciprocal of the intercept on the vertical axis, and the gradient of the straight line, respectively.

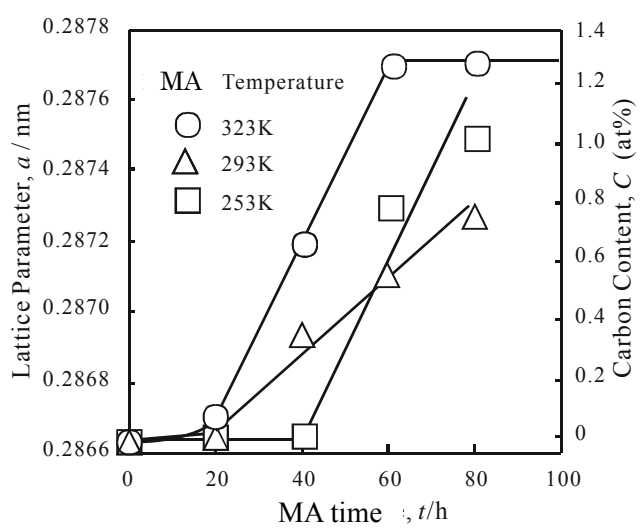

Figure 5. Changes in the lattice parameter and carbon content of iron solid solution with MA time.

Figures 6 and 7 show changes in the crystallite size and lattice strain as a function of MA time, respectively. For MA temperature of $323 \mathrm{~K}$, the crystallite size decreases with increasing MA time. On the other hand, for MA temperature 253 and $293 \mathrm{~K}$, 
before $20 \mathrm{~h}$ of MA there is no crystallite size change, while the lattice strain increases. As shown in Figure 5 , the amount of carbon atoms dissolved into iron during this period is too small; it can be considered that the increase in lattice strain is caused by plastic deformation of the powder. When MA time exceeds $20 \mathrm{~h}$, the crystallite size for $253 \mathrm{~K}$ is reduced remarkably, although the reduction of the crystallite size for $293 \mathrm{~K}$ is small. The crystallite size for $293 \mathrm{~K}$ decreases drastically as MA time exceeds $40 \mathrm{~h}$. For each MA temperature, it appears that the crystallite size saturates near about $6 \mathrm{~nm}$. As shown in Figure 7, the lattice strain for all MA temperatures increase first and their phenomena have a little different due to MA temperatures. When MA time exceeds $20 \mathrm{~h}$, the lattice strain for 253 and $323 \mathrm{~K}$ begins to decrease. While for $293 \mathrm{~K}$, it increases up to about $0.6 \times 10^{-2}$ first, and then decreases abruptly when MA time exceeds $40 \mathrm{~h}$.

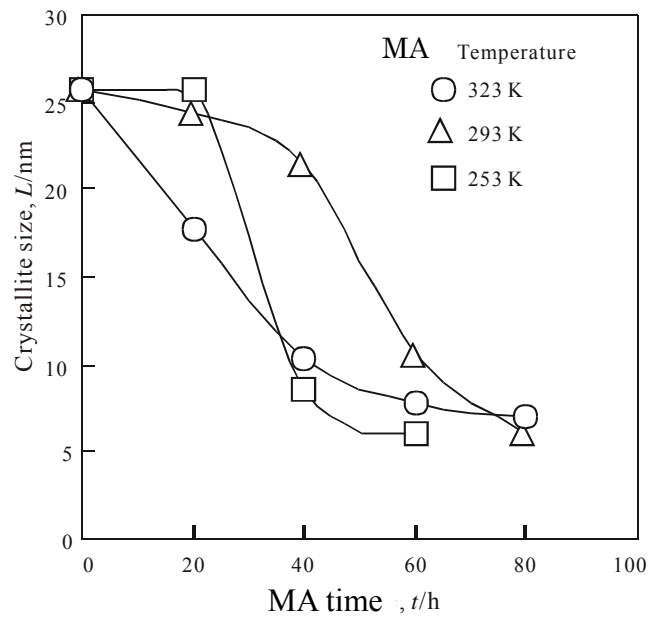

Figure 6. Change in the crystalline size as a function of MA time.

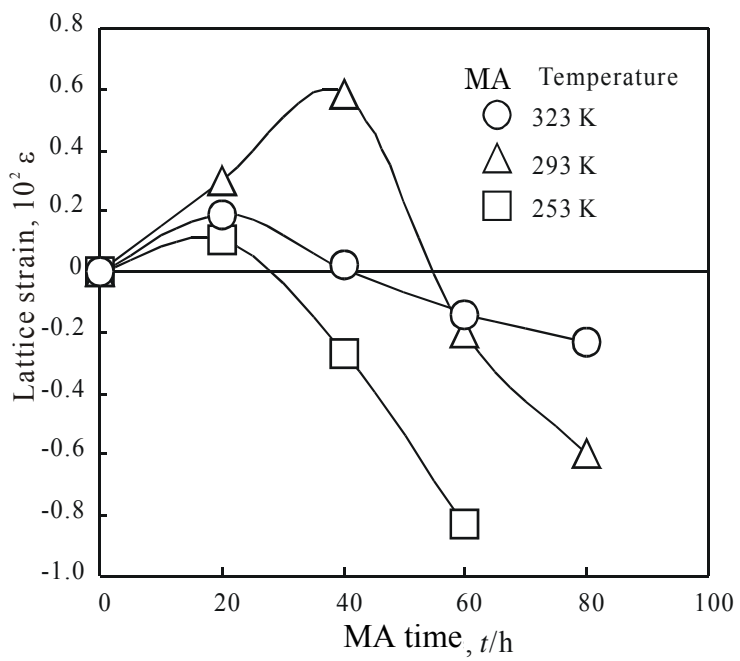

Figure 7. Change in the lattice strain of Fe-6C mixture powders as a function of MA time.

Figure 8 shows SEM images of Fe-6C mixture powders MAed for $80 \mathrm{~h}$ at various temperatures. After MAed for $80 \mathrm{~h}$, iron powders for each MA temperature have a slight difference in morphology. For milling temperature of $323 \mathrm{~K}$, the very fine particles aggregate to form flake-like powders. Due to the high MA temperature, the powders become softer and the refinement takes place at the early time of MA. As shown in Figure 8 (a), the powders still have the ability of plastic deformation. Contrary to this, very fine granular particles aggregate to form nodular powders at $253 \mathrm{~K}$. Brittle fracture is also partially observed. This suggests that the powders become brittle because of the low MA temperature and the brittle fracture takes place due to balls impact during MA. The powders MAed at $295 \mathrm{~K}$ have the middle morphology.
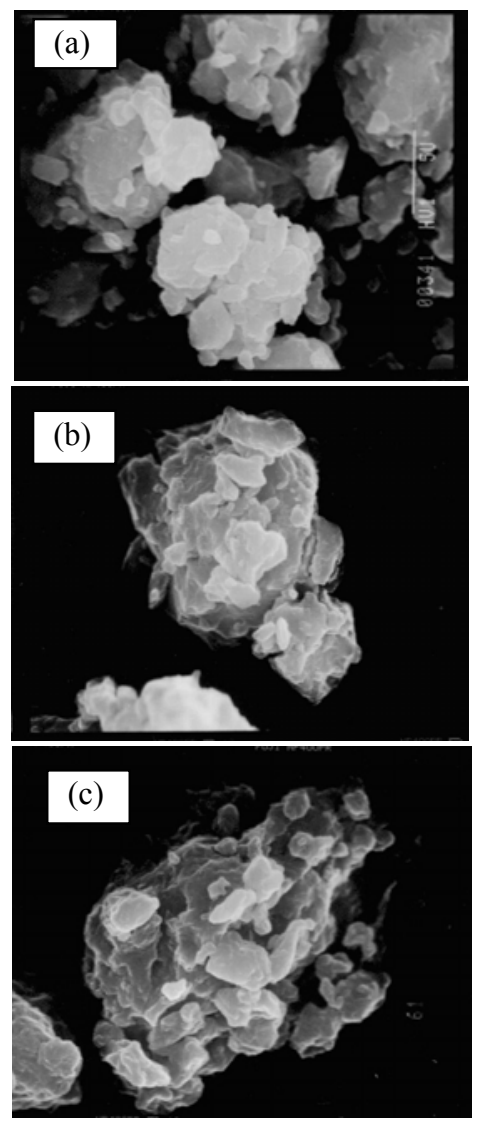

Figure 8. SEM images of Fe-6C mixture powders MAed at (a) $323 \mathrm{~K}$, (b) $293 \mathrm{~K}$ and (c) $253 \mathrm{~K}$ for $80 \mathrm{~h}$.

\subsection{Effect of MA rotation speed}

Figure 9 shows XRD patterns of Fe-7C-6Mn powders MAed at 120 and $80 \mathrm{rpm}$ for various time. For specimen MAed at $120 \mathrm{rpm}$ (Figure 9 (a)), the intensities of Bragg peaks for all elemental powders decrease rapidly with the increase of MA time. The carbon (0002) peak disappears when MA time exceeds $16 \mathrm{~h}$. For a specimen milled at $80 \mathrm{rpm}$ (Figure 9 (b)), the carbon peaks disappear after MAed for $60 \mathrm{~h}$. 

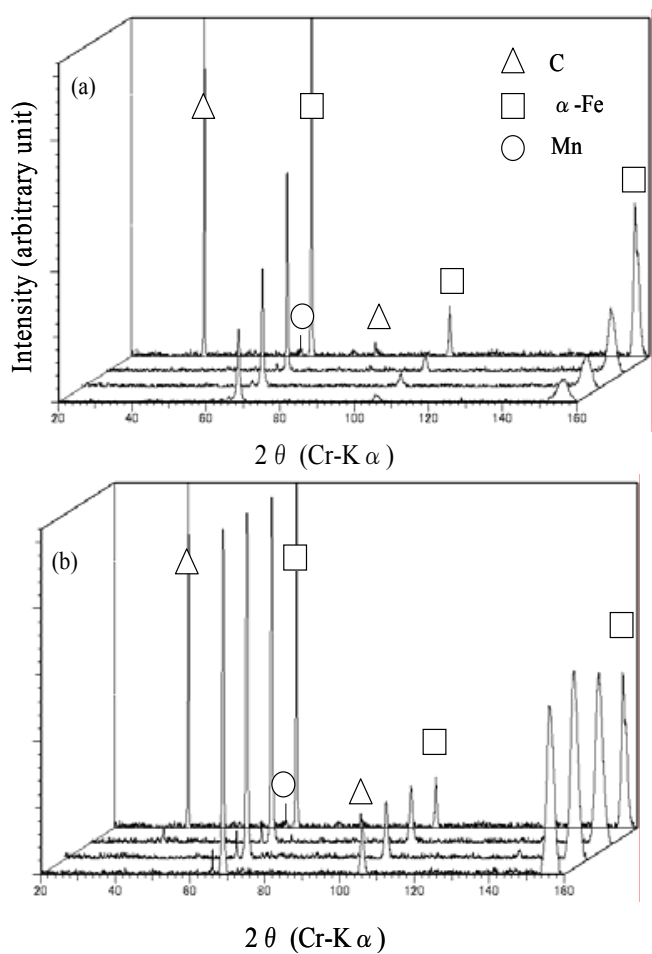

Figure 9. XRD patterns of Fe-7C-6Mn powders MAed at (a) 120 and (b) $80 \mathrm{rpm}$ for various time.

However, the peaks of elemental iron and manganese powders almost do not change their intensity as the MA time increases, even after $100 \mathrm{~h}$. Figure 10 illustrates XRD patterns of Fe-7C-6Mn system powders after MAed for $100 \mathrm{~h}$ as a function of rotation speed. The peaks of $\alpha-\mathrm{Fe}$ and $\mathrm{Mn}$ decrease with the increase of rotation speed. From Figure 9 and 10 , it can be assumed that the drastic reduction in the peak intensities for the specimen MAed at 120, may be due to a high impact energy, which is applied to powder particles.

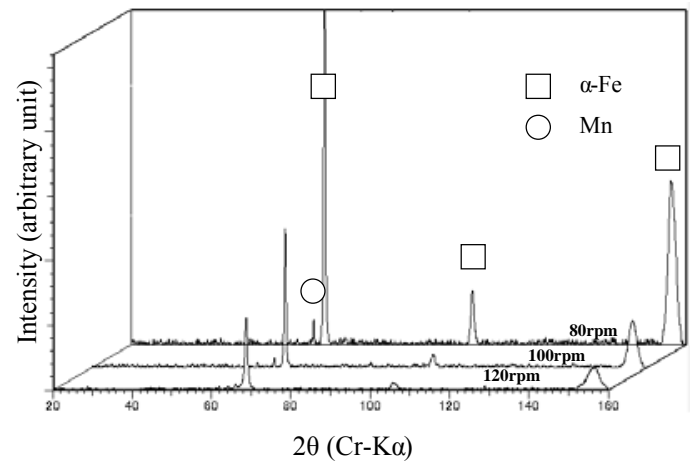

Figure 10. XRD patterns of $\mathrm{Fe}-6 \mathrm{C}-7 \mathrm{Mn}$ powders MAed for various time as a function of MA rotation speed.

Figure 11 shows changes in the lattice parameter and carbon content of Fe-7C-6Mn MAed at
80,100 and $120 \mathrm{rpm}$ as a function of MA time. In the cases of specimens MAed at 120 and $100 \mathrm{rpm}$, it is obvious that the lattice parameter and carbon content increase with increasing MA time. However, for the specimen MAed at $120 \mathrm{rpm}$, the increases are much greater than those observed in the specimen MAed at $100 \mathrm{rpm}$. This may be caused by the higher impact energy to the powder particles, which accelerates the dissolving of carbon atoms into iron lattice. On the other hand, for the specimen milled at 80 , there is almost no significant change with the increase of MA time. This may be due to the low impact energy applied to powder particles. From Figure 11, it can be seen that the solution of carbon atoms into the lattice iron almost does not take place when the rotation speed less than $80 \mathrm{rpm}$. Figure 12 shows how the lattice parameter and carbon content of specimens MAed for $100 \mathrm{~h}$ change with increasing the rotation speed. As shown in this figure, they increase abruptly as a function of rotation speed.

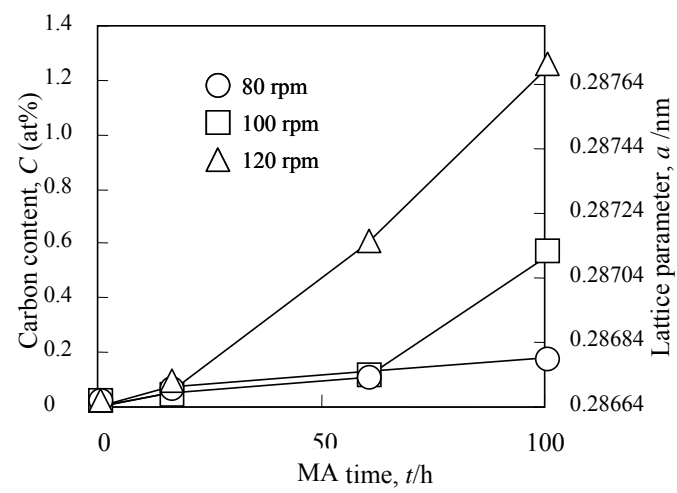

Figure 11. Change in the carbon content and lattice parameter as a function of MA time.

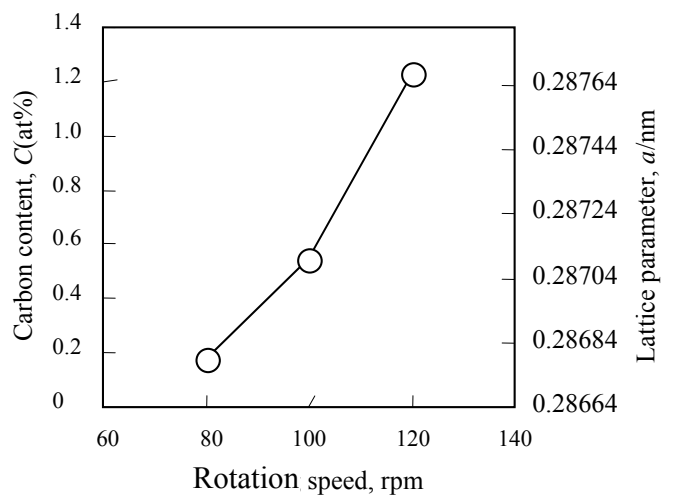

Figure 12. Change in the carbon content and lattice parameter as a function of rotation speed.

Figure 13 shows morphology of Fe-7C-6Mn mixture powders MAed at 80, 100 and $120 \mathrm{rpm}$ for various time. At the early stage of milling $(16 \mathrm{~h})$, the powder particles have a flake-like morphology. The lower the rotation speed, the blunter are the edges of the particles. Reduction of particle size progresses 
well with the increase of rotation speed. After $60 \mathrm{~h}$, in the specimen MAed at $120 \mathrm{rpm}$, the agglomerations of particles which occur by welding, mechanical interlocking of spongy or rough surfaces, or autohesion $^{(16)}$, start to break down to provide a narrow size distribution. With further MA $(100 \mathrm{~h})$, as the deagglomeration of the powders progresses, the particles became finer uniformly. On the other side, in the specimen milled at 100 and $80 \mathrm{rpm}$, the flake-like particles are still visible, even after MAed for $100 \mathrm{~h}$. And partially the deagglomeration of the powders occurs. It is observed that very fine nodular particles aggregate to form granular powders for specimen MAed at $100 \mathrm{rpm}$.
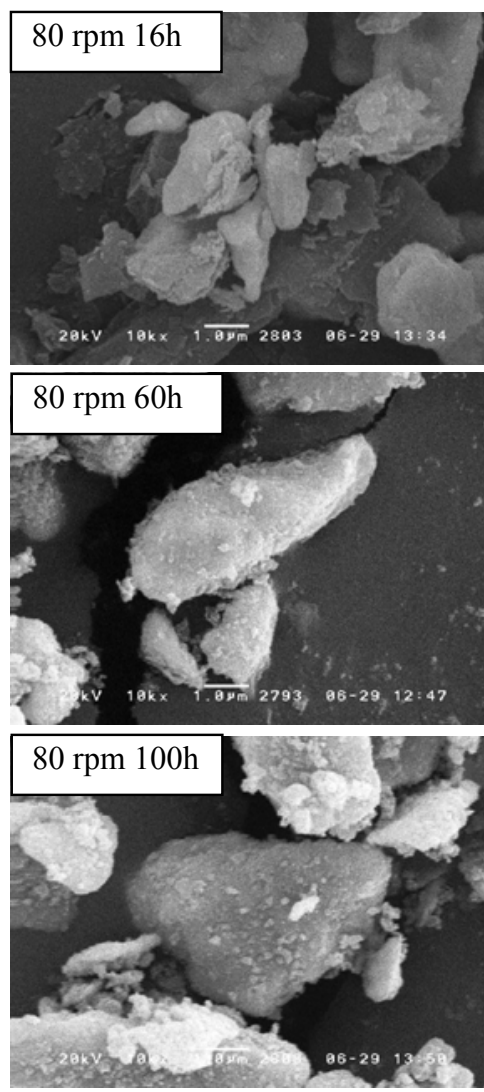
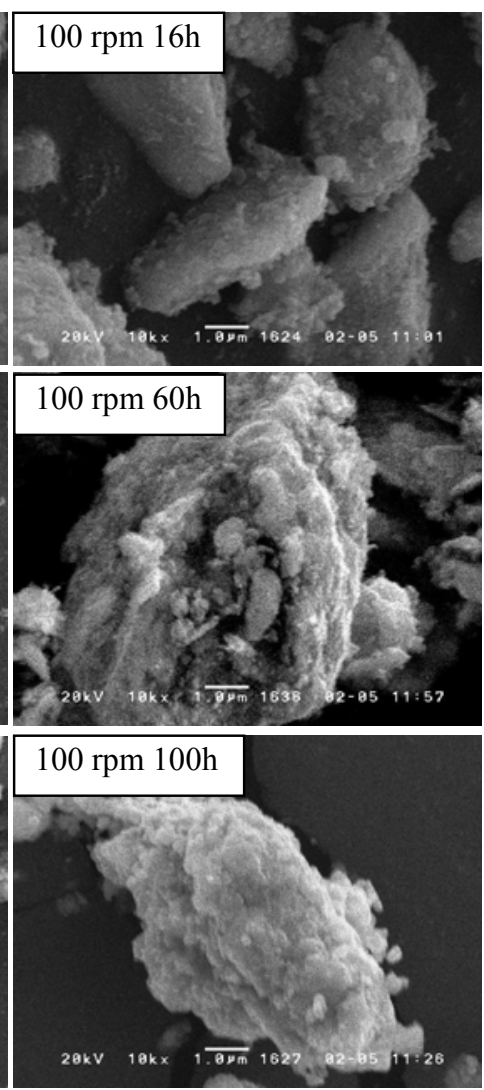
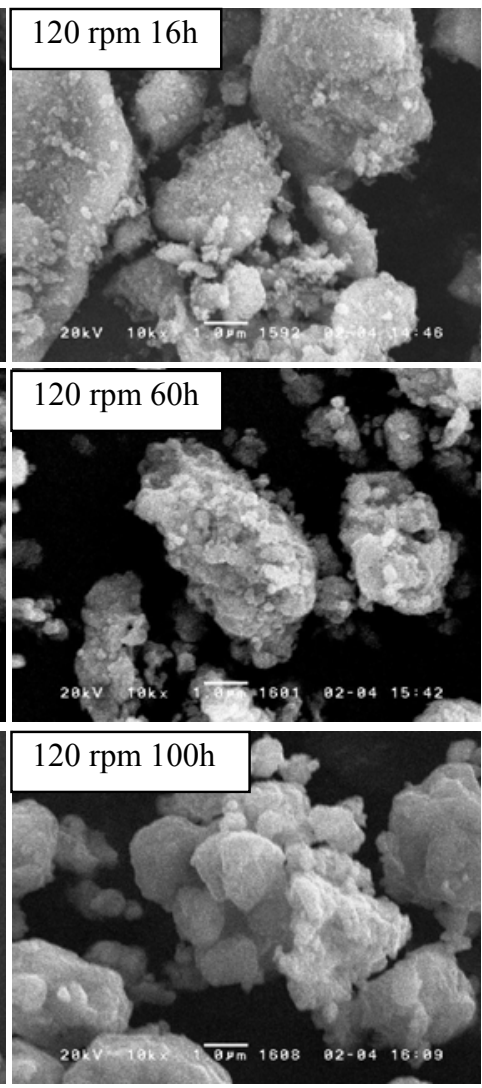

Figure 13. SEM images of Fe-7C-6Mn mixture powders MAed at 120, 100 and $80 \mathrm{rpm}$ for $100 \mathrm{~h}$.

\subsection{Effect of additive elements}

XRD patterns of Fe-C based system alloys MAed for $100 \mathrm{~h}$ are shown in Figure 14. The XRD analysis of (a) Fe-C-Si and (b) Fe-C-Cr system alloys carried out by using $\mathrm{Cu}-\mathrm{K} \alpha$ radiation, while for (c) $\mathrm{Fe}$ $\mathrm{C}-\mathrm{Mn}$, using $\mathrm{Cr}-\mathrm{K} \alpha$ radiation. Diffraction peaks of carbon disappeared when MA time is $100 \mathrm{~h}$ in all mixed powders, while diffraction peaks of $\alpha-\mathrm{Fe}$ broaden. These results indicate that a super-saturated solid solution and iron/ carbon amorphous phase are formed. As shown in Figure 14 (a), the diffraction peaks of additive element Si cannot be observed while the broadening diffraction peaks of $\mathrm{Mn}$ are detected and their intensities increase as a function of $\mathrm{Mn}$ concentration (see Figure 14 (c)). The disappearance of Si peak is considered to be caused by the formation of amorphous phase of $\mathrm{Fe} / \mathrm{C} / \mathrm{Si}$ powders due to MA. In the Fe-Si system, the formation of amorphous phase by MA was also reported by several researchers ${ }^{17,18)}$.
On the other hand, Miura et al., ${ }^{19)}$ observed the formation of amorphous phase in the MAed $\mathrm{Fe}_{68} \mathrm{Mn}_{15} \mathrm{C}_{17}$ (at \%) system alloy by using planetary ball mill for $200 \mathrm{~h}$. However, in the present study, the diffraction peaks of Mn broaden with the increase of MA time and are still observed for $100 \mathrm{~h}$ of MA. The additive element peaks of Mn may disappear after 200 $\mathrm{h}$ of MA, as reported. On the other hand, the diffraction peaks of $\mathrm{Fe}$ and $\mathrm{Cr}$ with bcc structure (Figure 14 (b)), almost have same positions, so that to evaluate the MA process in the $\mathrm{Fe}-\mathrm{C}-\mathrm{Cr}$ system powders using XRD analysis is very difficult. However, Kimura et al., ${ }^{20)}$ reported that in the MA of Fe-25Cr-(1.5-1.8)C (mass \%) system alloy by using vibratory ball mill for $200 \mathrm{~h}$, almost $\mathrm{Cr}$ atoms were dissolved into the $\alpha$-Fe lattice and the amorphous phase of $\mathrm{Fe} / \mathrm{C} / \mathrm{Cr}$ took place ${ }^{19}$. 

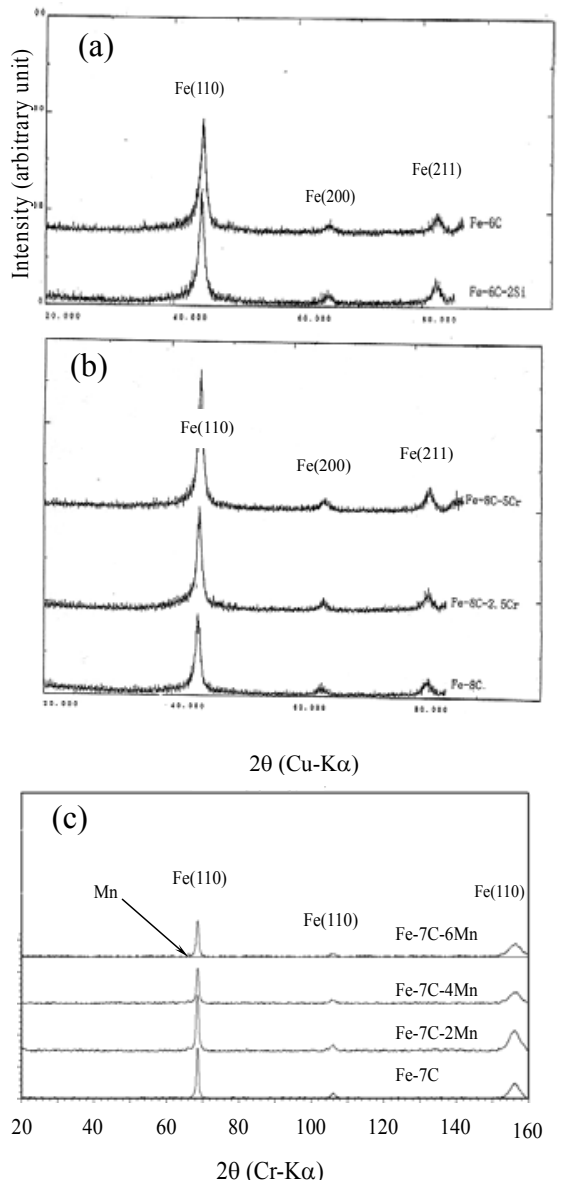

Figure 14. XRD patterns of (a) Fe-6C-Si, (b) Fe-7C$\mathrm{Mn}$ and (c) Fe-8C-Cr mixture powders MAed for $100 \mathrm{~h}$.

Figure 15 shows changes in the lattice parameter of $\alpha-\mathrm{Fe}$ and carbon content of $\mathrm{Fe}-\mathrm{C}-\mathrm{Mn}$ and $\mathrm{Fe}-\mathrm{C}-\mathrm{Cr}$ mixtures powders MAed for $100 \mathrm{~h}$. As shown there is no significant change in lattice parameter and carbon content with the increase of $\mathrm{Cr}$ or $\mathrm{Mn}$ concentration. It can be assumed that the addition of $\mathrm{Cr}$ or $\mathrm{Mn}$ in MAed Fe-C system alloy almost does not give an influence on the dissolution of carbon atoms into iron lattice. The amount of carbon atom dissolved into iron lattice is estimated to be a saturation concentration of about 1.30 at $\%$ as mentioned previously. In the case of $\mathrm{Fe}-\mathrm{C}-\mathrm{Cr}$ system alloy, it was also reported by Kimura $^{20}$ that the addition of $\mathrm{Cr}$ atoms in MAed Fe-C system did not affect significantly on the dissolution of carbon atoms into iron lattice.
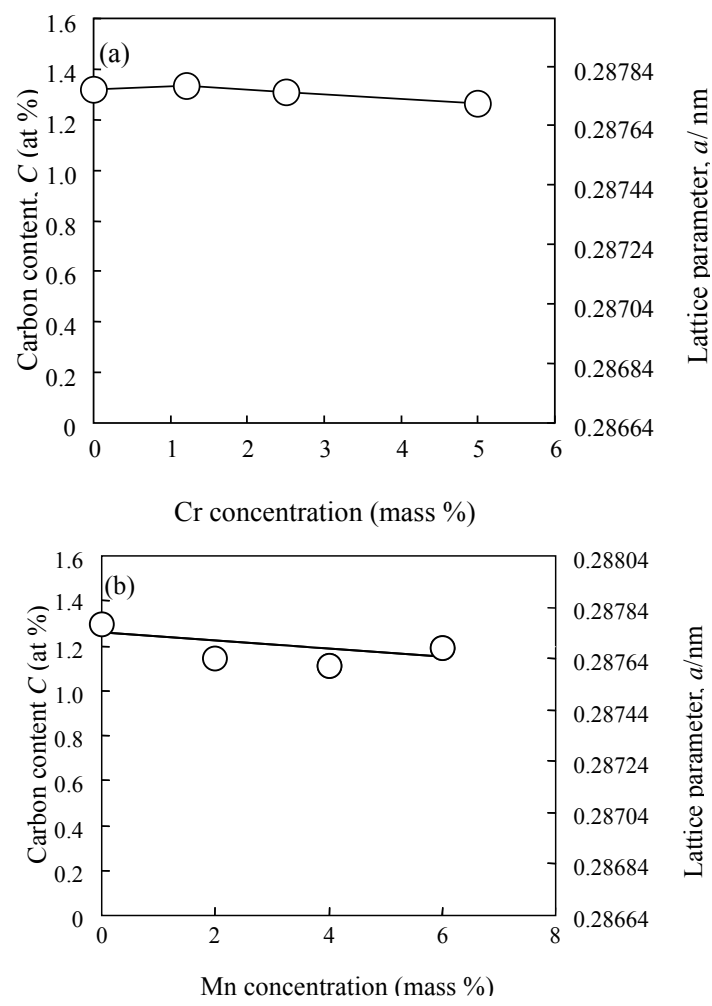

Figure 15. Changes in carbon content and lattice parameter after $100 \mathrm{~h}$ of milling as a function of (a) $\mathrm{Cr}$ or (b) Mn concentration.

Figure 16 shows DTA curves of Fe-C-Si, Fe-C$\mathrm{Cr}$ and Fe-C-Mn mixtured powders MAed for $100 \mathrm{~h}$. Each profile is characterized by a sharp exothermic peak around $580 \mathrm{~K}$ and a broad endothermic peak from 650 to $950 \mathrm{~K}$. The sharp exothermic peak around $580 \mathrm{~K}$ refers to the crystallization of amorphous phase ${ }^{5,8)}$, which exists in the MAed powders. The broad endothermic peak (caused by decomposition of carbide into $\alpha-\mathrm{Fe}$ and graphite; a process called graphitization) has a slightly different position depending on the composition of the MAed powders. In the case of the $\mathrm{Fe}-\mathrm{C}-\mathrm{Si}$ system alloys, the graphitization in $\mathrm{Fe}-6 \mathrm{C}-2 \mathrm{Si}$ system powders occurs (at about $720 \mathrm{~K}$ ) faster than that in Fe-6C system powders (at about $830 \mathrm{~K}$ ). Contrary to this, in the $\mathrm{Fe}-\mathrm{C}-\mathrm{Cr}$ and $\mathrm{Fe}-\mathrm{C}-\mathrm{Mn}$ system alloys, the intensity of the broad endothermic peak due to the graphitization decreases in the $\mathrm{Fe}-8 \mathrm{C}-\mathrm{Cr}$ and $\mathrm{Fe}-7 \mathrm{C}-\mathrm{Mn}$ system alloys, compared to $\mathrm{Fe}-\mathrm{C}$ system alloys. Thus, the addition of $\mathrm{Si}$ activates the graphitization, while the addition of $\mathrm{Cr}$ or $\mathrm{Mn}$ retards the graphitization. 

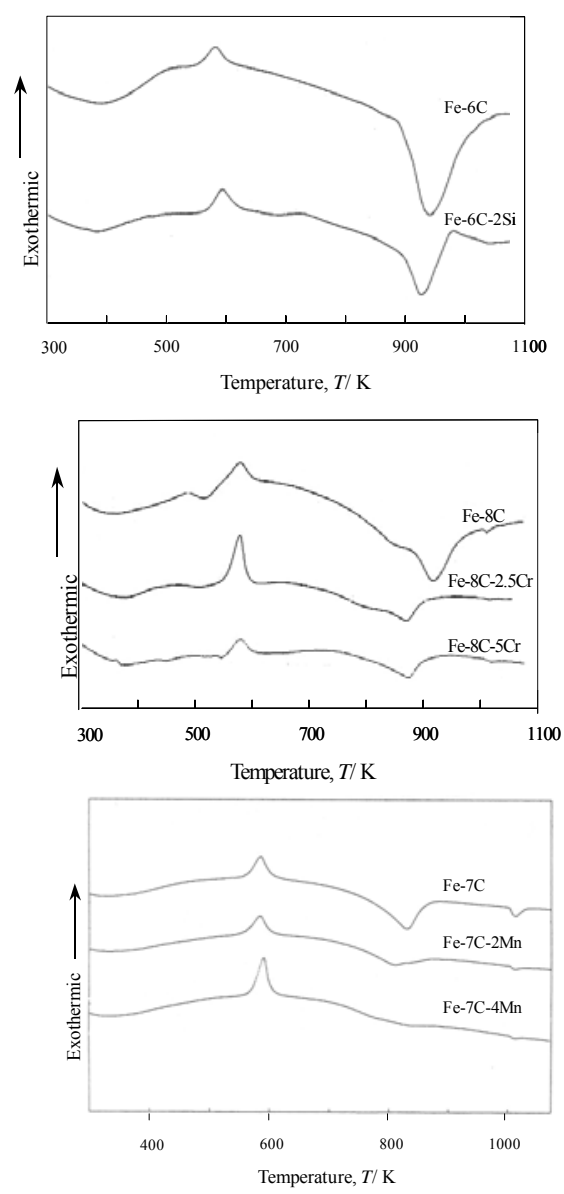

Figure 16. DTA curves of Fe-6C-Si, Fe-C-Cr and Fe7C-Mn system alloys MAed for $100 \mathrm{~h}$.

\section{Conclusion}

In Fe-C system based alloys, amorphization of graphite powders occurs first during the early stage of MA. With further MA, carbon atoms dissolve into iron lattice and reach the limitation value up to 1.3 at $\%$. Increasing MA time leads to the formation of ultrafine particles in the nano-meter order as a result of the kneading process.

The alloying mechanism depends on MA temperature. At high temperature $(323 \mathrm{~K})$, the supersaturated solid solution is formed in a short time. On the other hand, at low temperature $(253 \mathrm{~K})$ the refinement of particles by the brittle fracture accelerates the solution rate of carbon atoms into iron powders.

The progress of amorphization, solid solution and particles refinement are influenced by rotation speed. The higher the rotation speed (at $120 \mathrm{rpm}$ ) is the better their progress.
In any MA of $\mathrm{Fe}-\mathrm{C}$ based (Fe-C-Si, $\mathrm{Fe}-\mathrm{C}-\mathrm{Cr}$ and $\mathrm{Fe}-\mathrm{C}-\mathrm{Mn}$ ) system alloys, the solid solution and amorphization take place as well as in $\mathrm{MA}$ of $\mathrm{Fe}-\mathrm{C}$ system alloys. There is no significant change in the lattice parameter of iron and carbon content despite the increase of additive elements.

In MA of the ternary $\mathrm{Fe}-\mathrm{C}$ based system alloys, the addition of $\mathrm{Si}$ tends to activate the graphitization, while the addition of $\mathrm{Cr}$ or $\mathrm{Mn}$ retards the graphitization.

\section{References}

1. C.C.Koch, et al., Appl. Phy. Lett., 43, 1017, 1983.

2. R.B.Schwarz, R.R.Petrich and L.K.Saw, J. NonCryst. Solids, 76, 281, 1985

3. J. Saida, Y. Tanaka and K. Okazaki, Mat. Trans., JIM, 37, 265, 1996.

4. A.R. Yavari, Mechanical Alloying and Nanocrystalline Material, ISMANAM-94, Mat. Sci. Forum, 179, 1995.

5. Nurul Taufiqu Rochman et al., The $3^{\text {rd }}$ Pacific Rim Int. Conf. on Advanced Materials and Processing, TMS, 253, 1998.

6. Y. Kimura, S. Takaki and H. Goto, Powder and Powder Metallurgy, 43, 584, 1996.

7. Nurul Taufiqu Rochman et al., J. Mat. Proc. Tech., 89-90, 367, 1999.

8. T. Tanaka et al., Casting, 65, 25, 1993.

9. K. Nagano et al., J. Japan Society of Powder and Powder Metallurgy, 43, 738, 1996.

10. B.D. Cullity, Elementals of X-ray Diffraction, $2^{\text {nd }}$ Ed., Addison Wesley, Mass., 1978.

11. A. Serebryakov, Materials Science Forum, 88-90, 133, 1992.

12. E.J.Fasiska and H. Wagenblast, Trans. Metallurgical Society of AIME, 239, 18181967.

13. S. Saji et al., Materials Trans., JIM, 39, 778, 1998.

14. Nurul Taufiqu Rochman et al., J. Japan Soc. Heat Treatment, 39, 312, 1999.

15. I. Nitta, X-Ray Crystallography, $3^{\text {th }}$ ed., Maruzen, Tokyo, 1971.

16. The ASM Committee on Milling, "Milling of Brittle and Ductile Materials", Production of Met. Powder, p.56.

17. N. Malthourous-Gaffet and E. Gaffet, J. of Alloys and Compounds, 198, 143, 1993.

18. A.G. Escorial et al., Mater. Sci. and Eng., A134, 1394, 1991.

19. H. Miura, K. Omura and H. Ogawa, Mat. Trans., JIM, 36, 263, 1995.

20. Y. Kimura, S. Takaki and H. Gonto, J. the Japan Society of Powder and Powder Metallurgy, 45, 2831997. 